\title{
Risk stratification of patients undergoing pulmonary metastasectomy for soft tissue and bone sarcomas
}

\author{
Anthony Y. Lin, MD, ${ }^{\mathrm{a}}$ Svetlana Kotova, MD, ${ }^{\mathrm{a}, \mathrm{j}}$ Jane Yanagawa, MD, ${ }^{\mathrm{a}}$ Osama Elbuluk, BS, ${ }^{\mathrm{a}}$ \\ Gerald Wang, BS, ${ }^{\mathrm{b}}$ Nivedita Kar, BS, ${ }^{\mathrm{c}}$ David Elashoff, PhD, ${ }^{\mathrm{d}}$ Tristan Grogan, MS, \\ Robert B. Cameron, MD, ${ }^{\mathrm{a}, \mathrm{j}}$ Arun Singh, MD, ${ }^{\mathrm{e}}$ Bartosz Chmielowski, MD, ${ }^{\mathrm{e}}$ Noah Federman, MD, ${ }^{\mathrm{f}}$ \\ Scott D. Nelson, MD, ${ }^{g}$ Percy Lee, MD, ${ }^{\mathrm{h}}$ Fritz C. Eilber, MD, ${ }^{\mathrm{i}}$ and Jay M. Lee, $\mathrm{MD}^{\mathrm{a}}$
}

Objectives: Our objective was to identify risk factors associated with survival in patients who underwent pulmonary metastasectomy for soft tissue or bone sarcoma and to create a risk stratification model.

Methods: A retrospective review of the prospectively maintained University of California Los Angeles Sarcoma
Database was performed. Clinical, pathologic, and treatment variables were analyzed for overall survival and
disease-free survival. Univariate and multivariate analyses were performed, and variables that were identified as
significant were included to create a risk model. A total of 155 patients who underwent pulmonary metastasectomy
for soft tissue sarcoma ( $\mathrm{n}=108$ patients) or bone sarcoma ( $\mathrm{n}=47$ patients) from 1994 to 2010 were identified.

Results: Multivariate analysis identified 7 factors associated with poor overall survival: age more than 45 years, disease-free interval less than 1 year, thoracotomy, synchronous disease, location and type of sarcoma (soft tissue vs bone sarcoma), and performance of a lobectomy. The number of factors present was associated with poor overall survival, which varied widely from $64 \%$ in patients with 2 factors to $3 \%$ in those with 5 factors.

Conclusions: We have identified prognostic variables associated with overall survival after lung metastasectomy. Our model may be used as a risk stratification model to guide treatment decisions on the basis of the number of risk factors present. Although prospective studies are warranted to determine the benefit of surgical intervention in all cohorts compared with other local therapies or medical therapy, given the attendant dismal prognosis in patients with 5 or more risk factors, the benefit of surgical resection in this group is questioned. (J Thorac Cardiovasc Surg 2015;149:85-92)

\footnotetext{
From the Division of Thoracic Surgery, ${ }^{\text {a }}$ Department of Surgery, David Geffen School of Medicine at UCLA, Los Angeles, Calif; Division of Pulmonary and Critical Care Medicine, ${ }^{b}$ Department of Medicine, David Geffen School of Medicine at UCLA, Los Angeles, Calif; Departments of Biostatistics and Medicine, ${ }^{\mathrm{c}}$ David Geffen School of Medicine at UCLA, Los Angeles, Calif; Division of General Internal Medicine and Health Services Research, ${ }^{\mathrm{d}}$ David Geffen School of Medicine at UCLA, Los Angeles, Calif; Division of Hematology and Medical Oncology, Department of Medicine, David Geffen School of Medicine at UCLA, Los Angeles, Calif; Division of Pediatric Hematology and Medical Oncology, ${ }^{\mathrm{f}}$ Department of Pediatrics, David Geffen School of Medicine at UCLA, Los Angeles, Calif; Department of Pathology and Laboratory Medicine, ${ }^{\mathrm{g}}$ David Geffen School of Medicine at UCLA, Los Angeles, Calif; Department of Radiation Oncology, ${ }^{\text {h }}$ David Geffen School of Medicine at UCLA, Los Angeles, Calif; Division of Surgical Oncology, ${ }^{i}$ Department of Surgery, David Geffen School of Medicine at UCLA, Los Angeles, Calif; and Division of Thoracic Surgery, ${ }^{\mathrm{j}}$ Department of Surgery, Veterans Affairs Greater Los Angeles Healthcare System, Los Angeles, Calif. Funded by the Jonsson Comprehensive Cancer Center Sarcoma Program.

Disclosures: Arun Singh reports lecture fees from Biomarin. Percy Lee reports consulting and lecture fees from Viewray, Inc. Bartosz Chmielowski reports consulting fees from CytRx; consulting and lecture fees from Merck, BMS, and Genentech; and lecture fees from Prometheus and Amgen. The other authors have nothing to disclose with regard to commercial support.

Read at the 40th Annual Meeting of The Western Thoracic Surgical Association, Dana Point, California, June 25-28, 2014.

A.Y.L. and S.K. contributed equally to this article.

Received for publication June 25, 2014; revisions received Sept 8, 2014; accepted for publication Sept 12, 2014; available ahead of print Oct 12, 2014

Address for reprints: Jay M. Lee, MD, Ronald Reagan UCLA Medical Center, Division of Thoracic Surgery, Box 957313, Room 64-128 CHS, 10833 Le Conte Ave, Los Angeles, CA 90095-7313 (E-mail: jaymoonlee@mednet.ucla.edu). $0022-5223 / \$ 36.00$

Copyright (C) 2015 by The American Association for Thoracic Surgery http://dx.doi.org/10.1016/j.jtcvs.2014.09.039
}

See related commentary on pages 93-4.

Pulmonary metastases occur in up to $50 \%$ of patients with sarcoma during the course of their disease, ${ }^{1-3}$ and the lung is the sole site of metastasis in $19 \%$ of patients. ${ }^{4}$ No randomized controlled trials have directly compared surgical resection with chemotherapy alone or the effects of chemotherapy given for metastatic disease on survival. Pulmonary metastasectomy has become an accepted treatment option in select patients with metastatic sarcoma isolated to the lung. ${ }^{1-3,5-9}$ The prognosis for unresected disease is poor with a median survival of 11 months, whereas that for completely resected disease is up to 33 months. ${ }^{2}$ Retrospective studies have shown a survival advantage in patients who underwent complete resection of pulmonary metastases with 5-year survival ranging from $13 \%$ to $49 \%$. $^{1,10-12}$

Although multiple risk factors associated with poor survival have been reported, stratification of these variables into patient cohorts to guide surgical treatment is not well defined. ${ }^{2}$ The objective of this study is to identify prognostic variables of overall survival (OS) and create a risk stratification model to guide surgical treatment of sarcoma metastasis to the lung. 


\section{Abbreviations and Acronyms \\ BS = bone sarcoma \\ DFI = disease-free interval \\ DFS $=$ disease-free survival \\ OS = overall survival \\ STS = soft tissue sarcoma \\ VATS $=$ video-assisted thoracoscopic surgery}

We report the identification of 7 factors associated with poor OS after lung metastasectomy: age greater than 45 years, disease-free interval (DFI) less than 1 year, thoracotomy, synchronous disease, location and type of sarcoma (soft tissue sarcoma [STS] vs bone sarcoma $[\mathrm{BS}])$, and performance of lobectomy. The combination of these factors was associated with OS, which varied widely from $64 \%$ in patients with 2 factors to $3 \%$ in those with 5 factors.

\section{MATERIALS AND METHODS Patient Population}

A retrospective review of a prospectively maintained sarcoma database at our institution was queried to identify all patients who underwent pulmonary metastasectomy for sarcoma at the University of California, Los Angeles Medical Center between February 1994 and June 2010. Patients' records were reviewed to abstract the following data: demographics, type of primary sarcoma, initial therapy, time to pulmonary metastases, type of resection and additional therapy, disease-free survival (DFS), and OS. Follow-up was censored in May 2013. Three patients without any follow-up were excluded from the final analysis. Institutional review board approval was obtained.

\section{Preoperative Evaluation}

A multidisciplinary sarcoma tumor board evaluated patients with sarcomas metastatic to the lung preoperatively and postoperatively to determine the appropriateness of neoadjuvant and adjuvant treatments. All patients were considered for neoadjuvant chemotherapy followed by a single-stage or a 2-stage pulmonary metastasectomy for patients with bilateral diseases. Neoadjuvant chemotherapy was considered in those with (1) short DFI; (2) multiple lesions involving both lungs; (3) high-grade STS and high-risk BS (ie, osteosarcomas, Ewing's, and mesenchymal or dedifferentiated chondrosarcomas); and (4) synchronous pulmonary metastasis when neoadjuvant treatment was recommended for the primary lesion. Neoadjuvant therapy was defined as chemotherapy or chemoradiation given within 1 year before the pulmonary metastasectomy.

\section{Pathologic Evaluation}

All resected specimens were examined by a dedicated musculoskeletal pathologist. If the primary site resection was performed at an outside hospital, an attempt was made to obtain the original slides for our pathologist to confirm the diagnoses. The completeness of resection for the primary sites was determined from the available operative and pathology reports. The completeness of pulmonary metastasectomies was described using the residual tumor classification ( $\mathrm{R}$ stage) system. $\mathrm{R} 0$ was defined as a complete resection. R1 was defined as residual microscopic tumor. R2 was defined as gross residual tumor left at the time of lung resection, multiple nodules that were not all resected, and unresected primary tumors treated with nonsurgical modalities.

\section{Survival}

Patients' survival data were obtained from the hospital records and the Social Security Death Index. DFI was defined as the time from primary tumor resection to pulmonary metastasectomy performed at our institution. OS was defined as the time between the first pulmonary metastasectomy performed at our institution to the date of death or May 2013 (the date when data collection was censored). DFS was defined as the time from pulmonary metastasectomy to the date of recurrence at all sites. The date of pulmonary metastasectomy was used as the date of recurrence if R2 resection was performed at the time of the pulmonary metastasectomy.

The Kaplan-Meier method was used to calculate OS and DFS probabilities. All survival and recurrence dates were calculated from the date of the first pulmonary metastasectomy. In cases when a 2-stage or sequential resection was planned, the date of the second pulmonary metastasectomy was used if no other intervention was performed in between the 2 operations and if the interval between the 2 operations was less than 3 months.

\section{Statistical Analysis}

OS and DFS were graphically displayed using Kaplan-Meier curves. Survival estimates for 1,3 , and 5 years were extracted and plotted. Differences between groups were assessed by the log-rank test. Age, gender, sarcoma type, primary location, grade, size, margin, histology, DFI, metastasectomy approach, type of resection, pulmonary metastasis size, grade, margin status, neoadjuvant therapy, adjuvant treatments, and number of further metastasectomies (including other sites) were included as potential predictors of survival. Variables that were statistically significant from the log-rank test were included in a multivariable Cox proportional hazards model. Hazard ratio estimates and $95 \%$ confidence intervals were estimated from the final models. To more easily interpret the results, a scoring system was developed by categorically dichotomizing patients' characteristics to whether they displayed the significant prognostic variable or not. The patients were then grouped according to the number of negative prognosis variables. A Kaplan-Meier curve was constructed summarizing the relationship between the scoring system variable and survival. Statistical analyses were conducted in $\mathrm{R}$ (version 3.0.2, www.r-project.org).

\section{Patient and Clinical Presentation}

A total of 158 patients underwent pulmonary resection for metastatic sarcoma during the study period. Three patients without available long-term data were excluded from this analysis; therefore, the final analysis was based on the remaining 155 patients. Patient and primary tumor characteristics are shown in Table 1. Neoadjuvant and adjuvant therapies surrounding resection of the primary sarcoma are shown in Table 1. Twenty-one patients $(13.5 \%)$ underwent further resections for local recurrence before diagnosis of pulmonary metastases. Sixteen patients $(10.3 \%)$ had prior pulmonary metastasectomies at another institution, and 8 patients $(5.2 \%)$ had prior nonpulmonary metastasectomies.

\section{RESULTS \\ Characteristics of Pulmonary Metastases}

The characteristics of the resected pulmonary metastases are shown in Table 2. A total of 115 patients underwent open surgeries $(74.2 \%)$, and 40 patients $(25.8 \%)$ underwent video-assisted thoracoscopic surgery (VATS). Seven patients $(4.5 \%)$ underwent staged bilateral exploration. A total of 102 patients $(65.8 \%)$ underwent wedge resections, 27 patients $(17.4 \%)$ underwent lobectomy, and 6 patients $(3.9 \%)$ required pneumonectomy. The survival curves for the different types of resections 
TABLE 1. Patient and primary tumor characteristics

\begin{tabular}{|c|c|c|}
\hline & $\begin{array}{c}\text { Overall } \\
(n=155)\end{array}$ & $\begin{array}{c}\text { Percentage } \\
(\%) \\
\end{array}$ \\
\hline \multicolumn{3}{|l|}{ Age, y } \\
\hline Average & $47 \pm 17$ & \\
\hline Range & $11-92$ & \\
\hline \multicolumn{3}{|l|}{ Sex } \\
\hline Male & 87 & 56.1 \\
\hline Female & 68 & 43.9 \\
\hline \multicolumn{3}{|l|}{ Symptoms } \\
\hline Asymptomatic & 120 & 77.4 \\
\hline Symptomatic & 35 & 22.6 \\
\hline Cough & 13 & 8.4 \\
\hline Dyspnea & 8 & 5.2 \\
\hline Chest pain & 7 & 4.5 \\
\hline Hemoptysis & 4 & 2.6 \\
\hline Weight loss & 2 & 1.3 \\
\hline Nausea or vomiting & 1 & 0.6 \\
\hline \multicolumn{3}{|l|}{ Sarcoma type } \\
\hline Soft tissue & 108 & 69.6 \\
\hline Bone & 47 & 30.3 \\
\hline \multicolumn{3}{|l|}{ Primary tumor location } \\
\hline Extremity & 87 & 56.1 \\
\hline Nonextremity & 52 & 33.5 \\
\hline Chest wall* & 35 & 22.6 \\
\hline Intrathoracic $\oint$ & 4 & 2.6 \\
\hline Retroperitoneum & 7 & 4.5 \\
\hline Head and neck & 3 & 1.9 \\
\hline Other $\|$ & 3 & 1.9 \\
\hline Visceral-gynecologic & 16 & 10.3 \\
\hline \multicolumn{3}{|l|}{ Primary tumor diameter $(\mathrm{cm}) \dagger$} \\
\hline Average & $9.9 \pm 5.9$ & \\
\hline Range & $1.5-33.0$ & \\
\hline \multicolumn{3}{|l|}{ Primary tumor grade $\dagger$} \\
\hline High & 105 & 67.7 \\
\hline Low/intermediate & 19 & 12.2 \\
\hline Unknown & 31 & 20.0 \\
\hline \multicolumn{3}{|l|}{ Margin status } \\
\hline Positive & 15 & 9.7 \\
\hline Negative & 101 & 65.2 \\
\hline Unknown & 39 & 25.2 \\
\hline Neoadjuvant therapy & 62 & 40.0 \\
\hline Chemotherapy & 35 & 22.6 \\
\hline Chemoradiation & 26 & 16.8 \\
\hline Radiotherapy & 1 & 0.6 \\
\hline None & 89 & 57.4 \\
\hline Unknown & 4 & 2.6 \\
\hline Adjuvant therapy & 112 & 72.3 \\
\hline Chemotherapy & 55 & 35.5 \\
\hline Chemoradiation & 33 & 21.3 \\
\hline Radiotherapy & 24 & 15.5 \\
\hline None & 42 & 27.1 \\
\hline Unknown & 1 & 0.6 \\
\hline Reoperation for local recurrence & 21 & 13.5 \\
\hline \multicolumn{3}{|l|}{$\mathrm{DFI}(\mathrm{mo}) \ddagger$} \\
\hline Average & $34.4 \pm 37.8$ & \\
\hline
\end{tabular}

TABLE 1. Continued

\begin{tabular}{lcc}
\hline & $\begin{array}{c}\text { Overall } \\
(\mathbf{n}=\mathbf{1 5 5})\end{array}$ & $\begin{array}{c}\text { Percentage } \\
(\%)\end{array}$ \\
\hline Median & 20.4 \\
Range & $0.7-268.1$ \\
\hline$D F I$, Disease-free interval. *Includes breast. $\dagger$ A total of 55 patients had unknown \\
primary tumor diameters and were excluded. $\ddagger$ Time between resection of primary \\
tumor and pulmonary metastasectomy; 2 patients with unknown DFI, 4 patients \\
who did not undergo resection or underwent R2 resection were excluded. $\S$ Includes \\
pulmonary artery, mediastinum, and pleura. $\|$ Other includes abdomen, prostate, \\
and unknown.
\end{tabular}

are shown in Figure 1, $C$. The average number of resected metastases was 4 (range, 1-29) nodules. The average size of a dominant metastatic nodule was $2.9 \mathrm{~cm}$ (range, $0.3-16 \mathrm{~cm})$. High-grade histology was seen in the majority (101 patients, $65 \%$ ) of pulmonary metastases.

R0 resection was achieved in 105 patients $(67.7 \%)$. Thirteen patients underwent $\mathrm{R} 1$ resection, and 12 patients $(8.4 \%)$ underwent R2 resection. Twenty-three patients $(14.8 \%)$ had synchronous metastatic disease. The survival curves for type of sarcoma and synchronous metastases are shown in Figure 1, $A$ and $C$.

\section{Postoperative Complications}

The average length of stay was 4.8 days. Fifteen patients $(9.7 \%)$ experienced postoperative complications. Pneumonia, respiratory failure, atrial fibrillation, and persistent air leak and pneumothorax were most common and occurred in 9 patients $(5.8 \%)$. There were no 30 -day mortalities from the operative date.

\section{Recurrence of Metastases}

At an average follow-up of 14 months (range, 1.0-192.4 months), 19 patients showed no evidence of recurrence. Twenty-seven patients were lost to follow-up, and additional areas of metastases developed in 111 patients. Intrathoracic recurrences were seen in 79 patients. Of these, 75 patients developed second lung metastases, making it the most common site of systemic recurrence. Of these 111 patients with additional recurrences, 73 underwent 156 additional resections. Pulmonary re-resection was the most frequent procedure and was performed 94 additional times (range, 1-6). Re-resection of extremity recurrence was performed in 16 cases, and other organ resection was performed in 46 cases (Table 2).

\section{Prognostic Factors for Overall Survival and Recurrence}

The overall median survival was 35.4 months in this group of patients with known metastatic disease. The 5 -year OS and DFS for the entire study cohort were $34.8 \%$ and $7.7 \%$, respectively. However, we identified 
TABLE 2. Surgical resection of pulmonary metastases

\begin{tabular}{|c|c|c|}
\hline & Overall $(n=155)$ & Percentage $(\%)$ \\
\hline \multicolumn{3}{|l|}{ Pulmonary metastases resected } \\
\hline Average & $4 \pm 4$ & \\
\hline Range & $1-29$ & \\
\hline \multicolumn{3}{|c|}{ Diameter of largest pulmonary metastases $(\mathrm{cm})$} \\
\hline Average & $2.9 \pm 3.0$ & \\
\hline Range & $0.3-16$ & \\
\hline \multicolumn{3}{|l|}{ Operative approach } \\
\hline Open & 115 & 74.2 \\
\hline Thoracotomy & 79 & 51.0 \\
\hline Sternotomy & 21 & 13.5 \\
\hline Clamshell & 13 & 8.4 \\
\hline Hemiclamshell & 2 & 1.3 \\
\hline VATS & 40 & 25.8 \\
\hline Staged operation & 7 & 4.5 \\
\hline \multicolumn{3}{|l|}{ Type of resection } \\
\hline Wedge & 102 & 65.8 \\
\hline Segmentectomy & 20 & 12.9 \\
\hline Lobectomy & 27 & 17.4 \\
\hline Pneumonectomy & 6 & 3.9 \\
\hline \multicolumn{3}{|l|}{ Completeness of resection } \\
\hline R0 & 105 & 67.7 \\
\hline $\mathrm{R} 1$ & 13 & 8.4 \\
\hline $\mathrm{R} 2$ & 12 & 7.7 \\
\hline Unknown & 25 & 16.1 \\
\hline \multicolumn{3}{|l|}{ Grade } \\
\hline High & 101 & 65.2 \\
\hline Low/intermediate grade & 12 & 7.7 \\
\hline Unknown & 42 & 27.1 \\
\hline $\begin{array}{l}\text { Synchronous metastatic } \\
\text { disease }\end{array}$ & 23 & 14.8 \\
\hline Extremity & 3 & 1.9 \\
\hline Nonextremity & 20 & 12.9 \\
\hline Chest wall* & 11 & 7.1 \\
\hline Thoracic $\ddagger$ & 1 & 0.6 \\
\hline Other $\dagger$ & 8 & 5.2 \\
\hline \multicolumn{3}{|l|}{ Hospitalization (d) } \\
\hline Average & 4.8 & \\
\hline Range & $1-15$ & \\
\hline Complications & 15 & 9.7 \\
\hline $\begin{array}{l}\text { Pneumonia/respiratory } \\
\text { failure }\end{array}$ & 4 & 2.6 \\
\hline Atrial fibrillation & 3 & 1.9 \\
\hline $\begin{array}{l}\text { Persistent air leak/ } \\
\text { pneumothorax }\end{array}$ & 2 & 1.3 \\
\hline $\begin{array}{l}\text { Pleural effusion requiring } \\
\text { chest tube }\end{array}$ & 1 & 0.6 \\
\hline Wound infection & 1 & 0.6 \\
\hline Empyema & 1 & 0.6 \\
\hline Colitis & 1 & 0.6 \\
\hline Sternal dehiscence & 1 & 0.6 \\
\hline Bronchus injury & 1 & 0.6 \\
\hline 30-d mortality & 0 & 0 \\
\hline \multicolumn{3}{|l|}{ Outcome } \\
\hline Recurrence free & 19 & 12.3 \\
\hline Lost to follow-up & 27 & 17.4 \\
\hline
\end{tabular}

TABLE 2. Continued

\begin{tabular}{crc}
\hline & Overall $(\mathbf{n}=\mathbf{1 5 5})$ & Percentage (\%) \\
\hline Recurrence & 111 & 71.6 \\
Extremity & 7 & 4.5 \\
Nonextremity & 104 & 67.1 \\
Trunk* ${ }^{*}$ & 18 & 11.6 \\
Thoracic $\ddagger$ & 79 & 51.0 \\
Retroperitoneum & 1 & 0.6 \\
Head and neck & 1 & 0.6 \\
Other $\dagger$ & 5 & 3.2 \\
Patients who underwent & 73 & 47.1 \\
additional metastasectomies & & \\
Additional metastasectomies & 156 & \\
Pulmonary & 94 & \\
Range & $1-6$ & \\
Extremity & 16 & \\
Nonextremity & 46 & \\
Chest wall* & 10 & \\
Thoracic $\ddagger$ & 3 & \\
Head and neck & 2 & \\
Retroperitoneum & 1 & \\
Other $\dagger$ & 30 & \\
\hline
\end{tabular}

VATS, Video-assisted thoracoscopic surgery. *Includes breast. †Other includes liver, spine, back, bowel, abdomen, and brain. łIncludes lung, heart/pericardium, and mediastinum.

multiple characteristics that were associated with improved OS. Certain histologies were associated with longer survival, with leiomyosarcoma and osteosarcoma having the longest OS $(61 \%$ and $68 \%$ overall 5 -year survival, respectively), whereas liposarcoma and synovial sarcomas were associated with the shortest 5 -year OS of $17 \%$ and $19 \%$, respectively $(P=.02)$. There was no significant impact on DFS or OS by histologic grade of the pulmonary metastases or primary tumor characteristics (primary sarcoma grade, margin, and adjuvant therapy).

Patients who underwent wedge resection, segmentectomy, or pneumonectomy also had longer OS compared with those who underwent lobectomy $(P<.01)$. The type of operation (open vs VATS) was not associated with improved survival, but there was a trend with longer survival in the $25 \%$ of patients undergoing VATS (Table 3).

Synchronous disease, seen in $15 \%$ of patients at the time of pulmonary metastasectomy, was a negative predictor for OS $(22 \%$ vs $49 \%$ OS at 5 years; $P<.01)$. There was no impact on DFS. The OS at 5 years for R0, R1, and R2 resection was $41 \%, 46 \%$, and $25 \%$, respectively $(P<.50)$, suggesting that margin negativity beyond gross resection for pulmonary metastasectomy does not affect prognosis. Furthermore, 5-year survival for patients who underwent additional metastasectomies was $40 \%$ versus $44 \%$ for those who had any additional resection $(P=.25)$. Table 3 summarizes additional factors that correlate with DFS and OS. 



A

$\begin{array}{lllllll}\text { Soft }---- & 108 & 84 & 60 & 46 & 34 & 30 \\ \text { Bony }- & 47 & 42 & 37 & 30 & 27 & 24\end{array}$

B
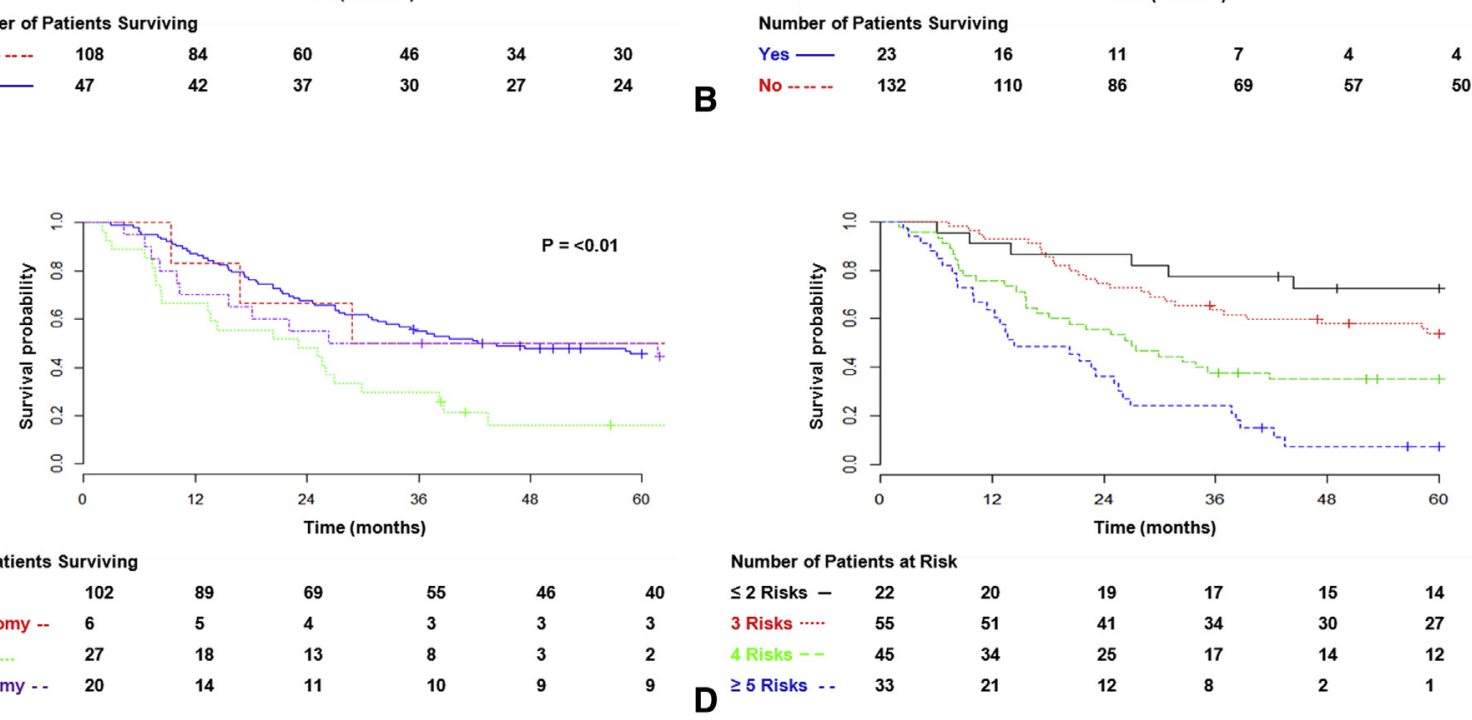

FIGURE 1. Overall 5-year survival in patients who underwent pulmonary metastasectomy according to (A) type of primary sarcoma, (B) presence of synchronous metastatic disease, (C) type of lung resection, and (D) total number of risk factors.

Multivariate analysis identified 7 negative predictors of OS: age greater than 45 years, DFI less than 1 year, thoracotomy, presence of synchronous disease, site of sarcoma (visceral gynecologic site vs not), type of sarcoma (STS vs BS), and performance of lobectomy (Table 4). The total number of negative risk factors $(<2,3$, or 4 or $>5$ factors) correlated with a poor OS at 5 years $(72 \%, 54 \%, 35 \%$, and $8 \%$, respectively). Corresponding survival curves are shown in Figure 1, $D$.

\section{DISCUSSION}

The lungs are the most common site of metastases in patients with sarcoma. The prognosis of these patients is variable and dependent on a multitude of factors. We report a modern series of patients undergoing pulmonary metastasectomy for sarcoma to identify prognostic factors for DFS and OS. Our findings are consistent with previous reports that age, DFI, presence of synchronous disease, and type of sarcomas (STS vs BS) predict OS. ${ }^{2,5,12,14-17}$

In addition, the extent of pulmonary resection predicts OS. Lobectomy compared with wedge resection or pneumonectomy was associated with poorer 5-year OS. Although lung-sparing operations are preferred, at times a central solitary lesion may mandate a larger pulmonary resection, such as pneumonectomy. In our series, patients who underwent lobectomy had worse survival compared with those who underwent pneumonectomy. Lobectomy was performed in patients with multiple metastases located in a single lobe, warranting the anatomic resection, whereas pneumonectomies were performed in patients with solitary central lesions. This may be reflective of greater metastatic disease burden and a more biologically aggressive disease in patients undergoing lobectomy compared with patients who underwent a pneumonectomy for a central solitary metastasis.

Furthermore, we report that the surgical approach to resection was not significant in predicting OS. Thoracotomy, median sternotomy, and clamshell incisions have been the traditional open approaches for pulmonary metastasectomy. Some believe that manual palpation is a critical part in detecting sarcoma pulmonary metastases, justifying an open surgical approach, particularly for patients with osteosarcoma. For instance, Kayton and colleagues $^{18}$ published their findings that CT scans underestimate the extent of metastatic disease in up to $35 \%$ pediatric and adolescent patients with osteosarcoma metastases to the lung, but they also found that approximately one third of the resected nodules were benign. 
TABLE 3. Predictors of disease-free and overall survival at specified times in patients with metastatic sarcoma to the lung

\begin{tabular}{|c|c|c|c|c|c|c|c|c|}
\hline & $N$ & $\begin{array}{c}\text { 1-Year } \\
\text { DFS }(\%)\end{array}$ & $\begin{array}{c}\text { 3-Year } \\
\text { DFS }(\%)\end{array}$ & $\begin{array}{c}\text { Log-rank } \\
P\end{array}$ & $\mathbf{N}$ & $\begin{array}{l}\text { 3-Year } \\
\text { OS }(\%)\end{array}$ & $\begin{array}{l}\text { 5-Year } \\
\text { OS }(\%)\end{array}$ & $\begin{array}{c}\text { Log-rank } \\
P\end{array}$ \\
\hline Gender & & & & .47 & & & & .15 \\
\hline Male & 76 & 38 & 15 & & 87 & 45 & 36 & \\
\hline Female & 61 & 34 & 11 & & 68 & 56 & 48 & \\
\hline Sarcoma type & & & & .16 & & & & .03 \\
\hline STS & 94 & 30 & 12 & & 108 & 44 & 37 & \\
\hline Bone & 43 & 48 & 16 & & 47 & 64 & 53 & \\
\hline Primary site & & & & .82 & & & & .51 \\
\hline Extremity & 77 & 36 & 14 & & 87 & 51 & 41 & \\
\hline Nonextremity & 46 & 35 & 12 & & 52 & 43 & 36 & \\
\hline Visceral-gynecologic & 14 & 44 & 18 & & 16 & 63 & 56 & \\
\hline Histology types & & & & $<.01$ & & & & .02 \\
\hline Leiomyosarcoma & 26 & 49 & 9 & & 29 & 69 & 61 & \\
\hline Osteosarcoma & 21 & 62 & 24 & & 22 & 73 & 68 & \\
\hline Synovial sarcoma & 19 & 21 & 5 & & 21 & 33 & 19 & \\
\hline Chondrosarcoma & 14 & 36 & 0 & & 14 & 57 & 43 & \\
\hline Liposarcoma & 10 & 12 & 0 & & 12 & 33 & 17 & \\
\hline Undifferentiated sarcoma $\dagger$ & 7 & 14 & 14 & & 9 & 38 & 25 & \\
\hline Ewing's sarcoma & 5 & 60 & 24 & & 7 & 43 & 43 & \\
\hline Malignant peripheral nerve tumor & 5 & 20 & 20 & & 4 & 40 & 20 & \\
\hline Alveolar soft part sarcoma & 3 & 0 & 0 & & 5 & 75 & 75 & \\
\hline Rhabdomyosarcoma & 2 & 100 & 0 & & 3 & 67 & 67 & \\
\hline Other & 25 & 27 & 11 & & 30 & 30 & 26 & \\
\hline Primary sarcoma grade* & & & & .75 & & & & .27 \\
\hline High & 93 & 34 & 18 & & 105 & 46 & 39 & \\
\hline Low/intermediate & 18 & 49 & 12 & & 19 & 68 & 58 & \\
\hline Primary sarcoma margin & & & & .06 & & & & .50 \\
\hline Positive & 15 & 7 & 0 & & 15 & 33 & 22 & \\
\hline Negative & 90 & 40 & 18 & & 101 & 50 & 43 & \\
\hline Adjuvant therapy for primary sarcoma & & & & .31 & & & & .25 \\
\hline Yes & 101 & 34 & 11 & & 112 & 45 & 38 & \\
\hline No & 35 & 40 & 23 & & 42 & 62 & 52 & \\
\hline Metastasectomy approach & & & & .40 & & & & .49 \\
\hline Open & 99 & 33 & 11 & & 115 & 47 & 37 & \\
\hline VATS & 38 & 46 & 20 & & 40 & 58 & 53 & \\
\hline Type of resection & & & & .07 & & & & $<.01$ \\
\hline Wedge & 94 & 43 & 17 & & 102 & 55 & 46 & \\
\hline Segmentectomy & 17 & 32 & 8 & & 20 & 50 & 50 & \\
\hline Lobectomy & 22 & 19 & 0 & & 27 & 30 & 16 & \\
\hline Pneumonectomy & 4 & 0 & 0 & & 6 & 50 & 50 & \\
\hline Grade of metastases* & & & & .62 & & & & .14 \\
\hline High & 91 & 33 & 15 & & 101 & 46 & 37 & \\
\hline Low/intermediate & 12 & 56 & 9 & & 12 & 83 & 75 & \\
\hline Metastasectomy margin & & & & .34 & & & & .54 \\
\hline $\mathrm{R} 0$ & 91 & 41 & 17 & & 105 & 50 & 41 & \\
\hline $\mathrm{R} 1$ & 12 & 29 & 10 & & 13 & 46 & 46 & \\
\hline $\mathrm{R} 2$ & & $\mathrm{n} / \mathrm{a}$ & $\mathrm{n} / \mathrm{a}$ & & 12 & 25 & 25 & \\
\hline Synchronous disease & & & & .11 & & & & $<.01$ \\
\hline Yes & 20 & 17 & 6 & & 23 & 38 & 22 & \\
\hline No & 117 & 39 & 15 & & 132 & 53 & 49 & \\
\hline $\begin{array}{l}\text { Neoadjuvant therapy for pulmonary } \\
\text { metastases }\end{array}$ & & & & .18 & & & & .15 \\
\hline Yes & 81 & 29 & 11 & & 93 & 62 & 52 & \\
\hline No & 56 & 45 & 16 & & 62 & 45 & 38 & \\
\hline Additional metastasectomies (all sites) & & & & .40 & & & & .25 \\
\hline
\end{tabular}


TABLE 3. Continued

\begin{tabular}{|c|c|c|c|c|c|c|c|c|}
\hline & $N$ & $\begin{array}{c}\text { 1-Year } \\
\text { DFS (\%) }\end{array}$ & $\begin{array}{c}\text { 3-Year } \\
\text { DFS (\%) }\end{array}$ & $\begin{array}{c}\text { Log-rank } \\
P \\
\end{array}$ & $\mathbf{N}$ & $\begin{array}{c}\text { 3-Year } \\
\text { OS }(\%)\end{array}$ & $\begin{array}{l}\text { 5-Year } \\
\text { OS }(\%)\end{array}$ & $\begin{array}{c}\text { Log-rank } \\
P \\
\end{array}$ \\
\hline Yes & 73 & 38 & 7 & & 73 & 59 & 44 & \\
\hline No & 64 & 35 & 23 & & 82 & 42 & 40 & \\
\hline
\end{tabular}

DFS, Disease-free survival; OS, overall survival; STS, soft tissue sarcoma; VATS, video-assisted thoracoscopic surgery; $n / a$, not applicable. *Patients with unknown grades were excluded. †Also known as malignant fibrous histiocytoma.

Despite a complete resection, further pulmonary metastases eventually will develop in $21 \%$ to $60 \%$ of these patients and a large number will require additional lung resections. ${ }^{11}$ We found that $70 \%$ of our patients had further metastatic disease, and in approximately half, the lung was their first site of recurrence after the initial pulmonary metastasectomy. The median time to a second pulmonary metastasis in our patient cohort was 6 months. Given the high pulmonary recurrence rate, microscopically complete resection (R0) and the need for an open approach may not be necessary in all instances. A minimally invasive approach by VATS (thoracoscopy) allows for faster recovery and less pain. ${ }^{1,3,12,15,19}$ In a retrospective study of 60 patients, Gossot and colleagues ${ }^{19}$ showed that thoracotomy and thoracoscopy were both feasible options for resection and found no statistically significant differences in survival at 1, 3, and 5 years. In our series, $25 \%$ of resections were done by VATS. Although in the univariate analyses, the surgical approach did not predict DFS or OS, in the multivariate analysis, we found that open surgery was actually a negative predictor of OS, reflecting a greater metastatic tumor burden requiring an open approach. Given that recurrence is high and a significant number of subjects will undergo multiple lung resections, a minimally invasive approach, if feasible, may be preferable in certain clinical situations depending on the tumor location and burden.

Pulmonary metastatic disease burden may be the most influential driver of the surgical approach. Weiser and colleagues $^{16}$ showed that the number of metastatic pulmonary nodules $(>3)$ and nodule diameter greater than $2 \mathrm{~cm}$ were negative prognostic factors of disease-specific 5 -year survival. Completeness of resection was a significant factor and correlated with disease-specific survival in the same study. However, other authors have reported that neither negative margin ${ }^{6}$ nor number of metastatic nodules correlates with survival. ${ }^{5,10}$ Our findings show that a positive microscopic margin did have a negative impact on the DFS but did not have a significant effect on OS (R0 and R1 resections had an OS of $41 \%$ and $46 \%$, respectively). Stephens and colleagues ${ }^{13}$ made a similar observation and did not find the completeness of resection to be a significant prognostic factor on OS.

Control of the primary tumor, absence of synchronous metastases, and ability to perform complete resection are traditional factors evaluated when patients are considered for pulmonary metastasectomy., ${ }^{3,12,15}$ Other groups have resected pulmonary metastases even in the presence of synchronous metastases. ${ }^{1,14}$ Blackmon and colleagues ${ }^{1}$ found no difference in OS when synchronous disease was present as long as extrathoracic and pulmonary sites of metastasis were resected compared with the patients who did not undergo resection. In addition, Smith and colleagues ${ }^{14}$ did not find that the presence of synchronous disease was significant in predicting OS, but complete resection was associated with the ability to attain longterm survival. In our series, $15 \%$ of patients had evidence of synchronous metastasis, and this carried a negative

TABLE 4. Predictors of overall survival (multivariate Cox proportional hazards model)

\begin{tabular}{lccr}
\hline & Hazard ratio & 95\% CI & \multicolumn{1}{c}{$\boldsymbol{P}$ value } \\
\hline Age $>45$ y & 1.99 & $1.23-3.23$ & $<.01$ \\
DFI $<1$ y (primary to metastasis) & 1.62 & $1.03-2.55$ & .04 \\
Resection* & & & \\
$\quad$ Pneumonectomy & 1.66 & $0.49-5.563$ & \\
Segmentectomy & 1.00 & $0.54-1.8$ & .41 \\
$\quad$ Lobectomy & 1.81 & $1.09-3.01$ & .99 \\
Synchronous disease & 2.22 & $1.23-3.97$ & .04 \\
STS & 2.23 & $1.31-3.78$ & \\
Primary site $\dagger$ & & & \\
$\quad$ Extremity & 2.76 & $1.25-6.08$ & \\
$\quad$ Nonextremity & 2.44 & $1.12-5.28$ & .01 \\
Open surgery & 2.03 & $1.17-3.49$ & .01 \\
\hline
\end{tabular}

CI, Confidence interval; DFI, disease-free interval; STS, soft tissue sarcoma. *Reference category is wedge resection. $\nmid$ Reference category is visceral-gynecologic site. 
impact on OS despite the fact that synchronous sites of disease were treated. The impact of synchronous metastasis on OS after lung metastasectomy may be reflective of variable treatments given at the extrathoracic synchronous sites, which included nonoperative modalities, and in some instances local therapies may not have been instituted.

\section{CONCLUSIONS}

Our study supports the existing body of evidence demonstrating that lung metastasectomy is associated with longterm OS. We have further defined a novel prognostic model using negative predictors of OS whereby an increasing number of risk factors correlated with worsening prognosis and survival. As such, OS at 5 years varied widely from $64 \%$ in patients with 2 risk factors to $3 \%$ in those with 5 identified risk factors. This stratification model can be used clinically to differentiate patients in high- and lowrisk categories, guide surveillance, and decide on the use of additional therapy after metastasectomy. Future randomized prospective studies are warranted, particularly in patients with a poor risk profile, to define whether any benefit is derived from lung metastasectomy compared with other local therapies or no resection. In the absence of control (nonoperative) data, quantifying the difference in survival among patients who have undergone metastasectomy and attributing it to surgical resection may not be accurate because there is a selection bias for lung metastasectomy. $^{20}$

\section{References}

1. Blackmon SH, Shah N, Roth JA, Correa AM, Vaporciyan AA, Rice DC, et al. Resection of pulmonary and extrapulmonary sarcomatous metastases is associated with long-term survival. Ann Thorac Surg. 2009;88:877-85.

2. Billingsley KG, Burt ME, Jara E, Ginsberg RJ, Woodruff JM, Leung DHY, et al. Pulmonary metastases from soft tissue sarcoma: analysis of patterns of diseases and postmetastasis survival. Ann Surg. 1999;229:602-10.

3. Rehders A, Hosch SB, Scheunemann P, Stoecklein NH, Knoefel WT, Peiper M. Benefit of surgical treatment of lung metastasis in soft tissue sarcoma. Arch Surg. 2007;142:70-5.
4. Gadd MA, Casper ES, Woodruff JM, McCormack PM, Brennan MF. Development and treatment of pulmonary metastases in adult patients with extremity soft tissue sarcoma. Ann Surg. 1993;218:705-12.

5. Harting MT, Blakely ML, Jaffe N, Cox CS Jr, Hayes-Jordan A, Benjamin RS, et al. Long-term survival after aggressive resection of pulmonary metastases among children and adolescents with osteosarcoma. J Pediatr Surg. 2006;41:194-9.

6. Kim S, Ott HC, Wright CD, Wain JC, Morse C, Gaissert HA, et al. Pulmonary resection of metastatic sarcoma: prognostic factors associated with improved outcomes. Ann Thorac Surg. 2011;92:1780-6.

7. Putnam JB Jr, Roth JA, Wesley MN, Johnston MR, Rosenberg SA. Analysis of prognostic factors in patients undergoing resection of pulmonary metastases from soft tissue sarcomas. J Thorac Cardiovasc Surg. 1984;87:260-8.

8. Casson AG, Putnam JB, Natarajan G, Johnston DA, Mountain C, McMurtrey M, et al. Five-year survival after pulmonary metastasectomy for adult soft tissue sarcoma. Cancer. 1992;69:662-8.

9. Jablons D, Steinberg SM, Roth J, Pittaluga S, Rosenberg SA, Pass HI. Metastasectomy for soft tissue sarcoma. Further evidence for efficacy and prognostic indicators. J Thorac Cardiovasc Surg. 1989;97:695-705.

10. Snyder CL, Saltzman DA, Ferrell KL, Thompson RC, Leonard AS. A new approach to the resection of pulmonary osteosarcoma metastases. Results of aggressive metastasectomy. Clin Orthop. 1991;270:247-53.

11. Treasure T, Fiorentino F, Scarci M, Møller H, Utley M. Pulmonary metastasectomy for sarcoma: a systematic review of reported outcomes in the context of Thames Cancer Registry data. BMJ Open. 2012;2.

12. Briccoli A, Rocca M, Salone M, Guzzardella GA, Balladelli A, Bacci G. High grade osteosarcoma of the extremities metastatic to the lung: long-term results in 323 patients treated combining surgery and chemotherapy, 1985-2005. Surg Oncol. 2010;19:193-9.

13. Stephens EH, Blackmon SH, Correa AM, Roth JA, Rice DC, Hofstetter W, et al. Progression after chemotherapy is a novel predictor of poor outcomes after pulmonary metastasectomy in sarcoma patients. J Am Coll Surg. 2011;212:821-6.

14. Smith R, Pak Y, Kraybill W, Kane JM III. Factors associated with actual longterm survival following soft tissue sarcoma pulmonary metastasectomy. Eur J Surg Oncol. 2009;35:356-61.

15. García Franco CE, Algarra SM, Ezcurra AT, Guillen-Grima F, San-Julian M, Midan JP, et al. Long-term results after resection for soft tissue sarcoma pulmonary metastases. Interact Cardiovasc Thorac Surg. 2009;9:223-6.

16. Weiser MR, Downey RJ, Leung DH, Brennan MF. Repeat resection of pulmonary metastases in patients with soft-tissue sarcoma. J Am Coll Surg. 2000; 191:184-90.

17. Buddingh EP, Anninga JK, Versteegh MIM, Taminiau AHM, Egeler RM, Van Rijswijk CSP, et al. Prognostic factors in pulmonary metastasized high-grade osteosarcoma. Pediatr Blood Cancer. 2010;54:216-21.

18. Kayton ML, Huvos AG, Casher J, Abramson SJ, Rosen NS, Wexler LH, et al. Computed tomographic scan of the chest underestimates the number of metastatic lesions in osteosarcoma. J Pediatr Surg. 2006;41:200-6.

19. Gossot D, Radu C, Girard P, Le Cesne A, Bonvalot S, Boudaya MS, et al. Resection of pulmonary metastases from sarcoma: can some patients benefit from a less invasive approach? Ann Thorac Surg. 2009;87:238-43.

20. Treasure T, Utley M. Surgical removal of asymptomatic pulmonary metastases: time for better evidence. BMJ. 2013;346:f824. 